D.O.I.: $10.3895 / \mathrm{S} 1808-04482009000300006$

\title{
ESTUDO MULTICASOS DOS IMPACTOS DO BUSINESS INTELLIGENCE NO PROCESSO DECISÓRIO E NA FORMULAÇÃO DE ESTRATÉGIAS
}

\section{MULTICASE STUDY OF THE IMPACTS OF BUSINESS INTELLIGENCE IN THE DECISION PROCESS AND IN STRATEGIES FORMULATION}

\author{
Stella Jacyszyn Bachega ${ }^{1}$; Néocles Alves Pereira ${ }^{2}$; Paulo Rogério Politano ${ }^{3}$ \\ ${ }^{1}$ Universidade Federal de Goiás - UFG - Catalão - Brasil \\ Universidade Federal de São Carlos - UFSCar - São Carlos - Brasil \\ stella@dep.ufscar.br \\ ${ }^{2}$ Universidade Federal de São Carlos - UFSCar - São Carlos - Brasil \\ dnap@power.ufscar.br \\ ${ }^{3}$ Universidade Federal de São Carlos - UFSCar - Ponta Grossa - Brasil \\ paulo@dc.ufscar.br
}

\begin{abstract}
Resumo
Cada vez mais as organizações necessitam de informações rápidas e confiáveis para agilizar o processo decisório e, assim, acompanhar o ambiente dinâmico em que estão inseridas. Dentre as ferramentas que auxiliam a construção dos Business Intelligence está o OLAP (On-Line Analytical Processing), que facilita a busca por informações. Permite a procura de dados relevantes com maior rapidez e visualização em perspectivas multidimensionais. O objetivo deste trabalho é identificar se a adoção da ferramenta de business intelligence OLAP pode ser considerada como uma alternativa de melhoria do processo decisório e de auxílio na formulação de estratégias. Quanto à metodologia, a presente pesquisa caracteriza-se por ser de abordagem qualitativa. $O$ procedimento utilizado foi o estudo de caso, mais especificamente um estudo multicasos. Foram entrevistadas oito empresas que utilizam o OLAP. Dentre os principais resultados, observou-se que esta ferramenta de apoio à decisão provoca melhorias no processo decisório e auxilia na elaboração de estratégias corporativas, de unidades de negócio e funcionais.
\end{abstract}

Palavras-chave: OLAP; business intelligence; processo decisório; formulação de estratégias.

\section{Definição do problema e objetivos do trabalho}

A manipulação de grandes massas de dados nas organizações torna-se cada vez mais fácil com os avanços da tecnologia da informação (TI). Todos estes esforços tecnológicos estimulam o alto índice de globalização, pois viabilizam as operações em nível mundial. Conforme Li (1996) e Decker e Focardi (1995), os avanços realizados na área de TI e o fato de as bases de dados armazenarem grandes volumes de dados têm cativado as empresas, que lidam com bases de dados volumosas, a conhecerem e entenderam profundamente esse bem valioso que possuem. 
Autores como Poe et al. (1998), Kimball (1997) e Inmon (1997) advogam que os processos de Data Warehousing e de Data Mining estão entre os avanços mais significativos em TI. O objetivo do Data Warehousing é atender as necessidades dos usuários no que tange ao armazenamento dos dados. Esse processo é útil para extrair e exibir de modo multidimensional, por meio das ferramentas OLAP (On-Line Analytical Processing), as informações necessárias aos responsáveis pelas tomadas de decisões em uma corporação. Data Mining, segundo Horst e Monard (2000) e Fayyad et al.(1996), consiste na aplicação de algoritmos apropriados e de análises de dados que produz um relacionamento particular de padrões a partir dos dados, gerando, assim, uma préavaliação dos resultados.

De acordo com SHIM et al. (2002), Data Warehouse, OLAP e Data Mining são ferramentas específicas que auxiliam na construção dos Business Intelligence (BI). Carvalho (2003, p. 103) afirma que:

[...] os sistemas de BI são mais elitizados, buscando atender às necessidades gerenciais. Um sistema de BI não é uma tecnologia que incentiva o compartilhamento de conhecimento entre as pessoas. O objetivo de um sistema de BI é contribuir para gerar novos conhecimentos que resultem em efetivos resultados empresariais de negócio (CARVALHO, 2003, p. 103).

O problema da presente pesquisa baseia-se na premissa de que a adoção de ferramentas de BI pelas empresas pode melhorar o processo decisório, bem como fornecer informações que auxiliem na obtenção de novas vantagens competitivas e na sustentação das já conquistadas neste ambiente turbulento em que a nova arma competitiva é a informação. Kaplan e Norton (1996) defendem que houve uma mudança no padrão de concorrência das organizações, nas quais passaram a competir, também, com base na informação. Assim, para obter e sustentar vantagens competitivas perante seus concorrentes, não basta apenas adotar rapidamente novas tecnologias, obter excelência em gestão etc., é necessário, também, possuir informações que auxiliem ao máximo o processo decisório nos diversos níveis empresariais (estratégico, tático e operacional).

Além disso, a presente pesquisa justifica-se, também, por haver poucas pesquisas que enfoquem as ferramentas de BI como apoiadoras do processo de formulação de estratégias (corporativas, de unidades de negócio e funcionais). Verificou-se que alguns autores, como Brodbeck et al. (2007), Carvalho et al. (2007), Rezende e Guagliardi (2007), Pires e Kato (2007), Sordi e Contador (2005), Caron-Fasan e Janissek-Muniz (2004), Brodbeck et al. (2003), Oliveira e Maçada (2003), Brodbeck e Hoppen (2002), Saccol et al. (2002), Rodrigues e Nunes (2001), Nogueira e Moreira (1997) consideram aspectos da tecnologia de informação sob enfoque estratégico, mas com objetivos diferentes ao aqui apresentado.

O objetivo desta pesquisa foi verificar, por meio de um estudo multicasos, se a adoção da ferramenta de business intelligence OLAP pode ser considerada como uma alternativa de melhoria 
do processo decisório e de auxílio na formulação de estratégias. Para tanto, foram consideradas nas empresas estudadas, particularidades dos seguintes períodos: i) anterior à implantação do OLAP; ii) de implantação do OLAP; e iii) pós-implantação do OLAP. Ressalta-se que neste trabalho focou-se o OLAP por esta ferramenta possuir a intenção de facilitar a busca por informações em Data Wharehouses, permitindo a procura de dados relevantes, com maior rapidez e visualização em perspectivas multidimensionais; além do fato de todas as empresas acessíveis ao estudo possuírem tal ferramenta e um histórico de informações sobre os períodos analisados.

A estrutura do presente artigo é a que segue: na próxima seção, os principais conceitos sobre o tema aqui abordado são expostos brevemente; na seção três encontra-se a metodologia da pesquisa; na quarta seção há a exposição de um breve histórico das empresas pesquisadas; na seção cinco há a apresentação dos casos, seguida pela seção de análise destes; e na sétima seção está a conclusão da pesquisa.

\section{Referencial teórico}

Nesta seção, conceitos relativos à estratégia, hierarquia estratégica e processo decisório são expostos brevemente, como forma de contextualizar o leitor sobre os principais pontos abordados na pesquisa realizada. Além disso, são apresentados aspectos importantes sobre o OLAP (On-Line Analytical Processing).

\subsection{Estratégia e Hierarquia Estratégica}

Uma definição de estratégia que seja aceita universalmente não é encontrada, apesar de existir enorme volume de literatura sobre o assunto. Segundo Ginsberg (1984 apud GIMENEZ, 2000), o termo estratégia é utilizado muitas vezes sem necessárias clarificações, dificultando o desenvolvimento de abordagens integradoras, no que tange ao estudo de estratégia organizacional.

Segundo Mintzberg e Quinn (2001) e Mintzberg (1991), estratégia pode ser entendida como plano, manobra (ploy), padrão, posição e perspectiva, caracterizando os “cinco Ps" da estratégia. O Quadro 1 aponta esses cinco sentidos para o conceito estratégia.

Como pode ser inferido pelo exposto, o termo estratégia gera conflitos quanto a uma única definição. Slack et al. (2002) defende a idéia de que o conceito de estratégia empresarial depende parcialmente do que se entende por "a organização". Na visão de Porter (1998), uma empresa diversificada possui dois níveis de estratégia: a estratégia das unidades de negócios (ou competitiva) e a estratégia corporativa (ou da totalidade do grupo empresarial). 
Quadro 1- Os cinco "Ps" da estratégia

\begin{tabular}{|l|l|}
\hline Conceito de Estratégia & \multicolumn{1}{c|}{ Definição } \\
\hline Plano & $\begin{array}{l}\text { A estratégia pode ser definida como um plano, um curso de ação intencionalmente } \\
\text { elaborado para guiar a organização através do tempo. }\end{array}$ \\
\hline Manobra (Ploy) & $\begin{array}{l}\text { A estratégia pode ser empregada para comunicar uma mensagem falsa ou não, iludir } \\
\text { ou confundir os concorrentes. }\end{array}$ \\
\hline Padrão & $\begin{array}{l}\text { As estratégias são emergentes, surgindo sem intenção. A tendência natural é de } \\
\text { incorporação ao comportamento quando determinado curso de ação traz resultados } \\
\text { positivos. }\end{array}$ \\
\hline Posição & $\begin{array}{l}\text { A estratégia é definida como busca por um posicionamento que a sustente e defenda } \\
\text { sua posição na indústria ou no nicho em que a empresa atua. }\end{array}$ \\
\hline Perspectiva & $\begin{array}{l}\text { A estratégia refere-se ao modo como a organização se percebe diante do mercado. } \\
\text { Possui relação com a percepção interna da organização, cultura, e a ideologia. }\end{array}$ \\
\hline
\end{tabular}

Fonte: Adaptado de Mintzberg e Quinn (2001) e Mintzberg (1991)

No entanto, de acordo com Slack et al. (2002), existem três níveis da estratégia que formam, assim, uma hierarquia. Essa visão hierárquica da estratégia foi proposta inicialmente por Hayes e Wheelwright (1984), abrangendo as estratégias corporativa, de negócio e funcional, a saber:

- Estratégia corporativa: são ações predefinidas que "guiam” a corporação no ambiente global, econômico, social e político em que está inserida;

- Estratégia da unidade de negócio: Uma unidade de negócios é uma empresa, uma unidade fabril ou uma linha de produtos dentro de uma corporação (PIRES, 1995). Esta estratégia orienta cada negócio da organização, individualmente, estabelecendo a missão, os objetivos, e definindo como almejam competir em seus mercados;

- Estratégia funcional: consiste na estratégia delimitada pelas devidas funções do negócio (produção, finanças, marketing, pesquisa e desenvolvimento, etc.). Conduz as ações no ambiente do negócio a que pertence de forma a contribuir com os objetivos estratégicos e/ou competitivos deste.

Destaca-se que nesta pesquisa, utilizou-se a abordagem hierárquica da estratégia conforme Hayes e Wheelwright (1984) no roteiro elaborado para a orientar as entrevistas nas empresas.

Assim, para que a corporação atinja seus objetivos, deve haver sinergia/integração entre as estratégias corporativa, de negócio e funcional, obedecendo à hierarquia: as estratégias funcionais são delineadas com base nas estratégias de negócio e estas, por sua vez, se orientam nas estratégias corporativas. Nesse contexto, Bachega e Godinho Filho (2005) apontam a existência de sete tipos de integração, dentre eles a integração entre as decisões funcionais, integração entre as decisões e as áreas de decisões funcionais, e integração entre as decisões e estratégias funcionais. Visto a importância das decisões no âmbito organizacional, na seção seguinte é abordado o processo decisório. 


\subsection{Processo Decisório}

Uma decisão, de acordo com Turban et al. (2005), diz respeito a uma escolha feita entre duas ou mais alternativas, na qual esta pode ser tomada constantemente por indivíduos ou por grupos. As decisões possuem estrutura, segundo O’Brien (2004), e obedecem a um processo conforme as visões de Simon (1977) e Thomsen (2002).

As decisões organizacionais são estruturadas quanto aos níveis estratégico, tático e operacional. O’Brien (2004) advoga que as decisões realizadas no nível operacional são mais estruturadas. Envolvem situações em que os procedimentos a serem seguidos podem ser previamente especificados, quando uma decisão se faz necessária. Quanto ao nível tático, as decisões tendem a ser semi-estruturadas. Apenas alguns procedimentos de decisão podem ser préestabelecidos, mas não o suficiente para resultar em uma decisão definida. As decisões não estruturadas são tomadas no nível estratégico e englobam situações nas quais os procedimentos a serem seguidos são praticamente impossíveis de prévia especificação.

O processo decisório, conforme Simon (1977), é composto pelas fases de inteligência, projeto e escolha. O processo inicia com a fase inteligência. Durante esse processo, o tomador de decisão está em busca de informação ou conhecimento que sugira a presença do problema ou a necessidade de decisão. Na fase de projeto, uma vez que o problema foi identificado e formalmente definido, o tomador de decisão deve iniciar atividades referentes à formação e análise de alternativas, com o intento de procurar soluções potenciais para o problema. Finalmente, na fase de escolha, o decisor seleciona uma das alternativas de solução disponíveis, geradas e analisadas na fase anterior. A fase de implementação da decisão foi adicionada ao processo decisório posteriormente, constituindo-se em um processo de quatro fases.

Devido à complexidade do processo decisório é que o desenvolvimento de ferramentas de apoio à decisão tomam importância. Essas ferramentas auxiliam no fornecimento de informações antes não possíveis de serem obtidas por meio de uma simples observação das grandes massas de dados armazenadas nas empresas. Dentre estas ferramentas encontra-se o OLAP (On-Line Analytical Processing), que é tratado na próxima seção.

\subsection{OLAP (On-Line Analytical Processing)}

O termo On-Line Analytical Processing (processamento analítico on-line - OLAP), segundo Turban e Aronson (2001), refere-se a uma variedade de atividades usualmente executadas pelos usuários finais em sistemas on-line. Laudon e Laudon (2004) utilizam a expressão análise multidimensional de dados para se referirem a esta ferramenta de apoio à decisão. Turban et al. 
(2005, p. 86) interpretam o OLAP como "uma categoria ampla de aplicações e técnicas para coletar, armazenar, analisar, fornecer acesso aos dados e ajudar os usuários da empresa a fazerem melhores negócios e tomarem melhores decisões estratégicas".

Nesse artigo, o OLAP é considerado uma ferramenta de apoio à decisão que permite a análise multidimensional de dados em sistemas on-line e, com isso, auxilia a empresa a tomar decisões mais eficientes e eficazes nos diversos níveis empresariais (operacional, tático e estratégico). Portanto, tal ferramenta também pode apoiar na elaboração de estratégias corporativas, de unidades de negócio e funcionais.

O OLAP, estruturalmente, é feito de numerosos cenários especulativos (“o que se” e/ou "porque") de modelos de dados executados dentro do contexto de algumas bases históricas e perspectivas. Dentro destes cenários, os valores das variáveis chave ou parâmetros são mudados com freqüente repetição, para refletir potenciais variâncias no suprimento, produção, economia, vendas, mercado, custos, e/ou outros fatores ambientais e internos a empresa (CODD et al., 2005).

Os requisitos funcionais do OLAP são (THOMSEN, 2002, p.04): i) dimensões e cálculos dimensionais especificados de modo eficaz; ii) rica estruturação dimensional, com referência hierárquica; iii) separação entre estrutura e representação; iv) suporte multiusuário; v) velocidade suficiente para apoiar à análise ocasional; vi) flexibilidade.

Conforme Kurz (1999, apud RICHTER, 2001), quanto aos padrões de armazenamento do cubo de dados, existem o ROLAP (Relational On-Line Analytical Processing - OLAP relacional), o MOLAP (Multidimensional On-Line Analytical Processing - OLAP multidimensional), o HOLAP (Hybrid On-Line Analytical Processing - OLAP híbrido), o DOLAP (Desktop On-Line Analytical Processing) e o FFOLAP (Flat-Filed On-Line Analytical Processing). Salienta-se que a necessidade de dados do OLAP geralmente é suprida pelo data warehouse, que é um conjunto de banco de dados integrados que proporciona aos usuários uma fonte única de informação da empresa, sendo utilizada também como ferramenta de suporte ao processo de extração de conhecimento (KIMBALL; ROSS, 2002).

Existem pesquisas realizadas com o intento de melhorar o desempenho das consultas realizadas pelo OLAP. Park et al. (2002) propuseram um novo algoritmo para reescrever as consultas OLAP, com intuito de melhorar a usabilidade das visões materializadas. Castro et al. (2004) aplicam o OLAP na estratégia de vendas com o intuito de alavancar a gestão da cadeia de suprimentos. 


\section{Metodologia de pesquisa}

A abordagem da presente pesquisa é qualitativa. Conforme Bryman (1989), a característica mais central da pesquisa qualitativa, em contraste com a quantitativa, é sua ênfase na perspectiva do objeto a ser estudado.

Quanto ao procedimento de pesquisa, foi utilizado o estudo de caso, mais especificamente um estudo multicasos. De acordo com Yin (1994), uma pesquisa do tipo estudo de caso pode incluir tanto um único estudo de caso quanto um estudo multicasos. Além disso, um estudo de caso pode conter ou ser limitado a evidências quantitativas, não devendo ser taxada sempre com uma pesquisa qualitativa.

A análise dos dados qualitativos foi procedida por meio da análise de conteúdo segundo Bardin (2000). Conforme esse autor, a análise de conteúdo designa um conjunto de técnicas das comunicações visando a obter, por procedimentos sistemáticos e objetivos de descrição do conteúdo das mensagens, indicadores (quantitativos ou não) que permitam a inferência de conhecimentos relativos às condições de produção/recepção (variáveis inferidas) destas mensagens.

Os dados foram coletados nas empresas com o auxílio de um roteiro semi-estruturado (questões abertas e fechadas) contendo 26 questões relativas aos períodos anteriores à implantação, de implantação e pós-implantação do OLAP e as entrevistas foram gravadas quando permitido.

Foram entrevistadas oito empresas, denominadas neste artigo de empresas 'Alfa', 'Beta', 'Gama', 'Delta', 'Omega', 'Lambda', 'Theta' e 'Sigma' por questões de sigilo. Na empresa Alfa o funcionário entrevistado foi o Analista de Sistemas. O entrevistado na empresa Beta foi o Analista de Sistemas Sênior e nas empresas Gama e Omega foram questionados os respectivos Gerentes de Tecnologia da Informação (TI), sendo que na empresa Omega houve também a participação do Diretor Administrativo na entrevista. Na empresa Delta o entrevistado foi o Chefe do Departamento de Suporte Técnico e na empresa Lambda foi o Gerente de Business Intelligence. Já nas empresas Theta e Sigma os entrevistados foram, respectivamente, o Coordenador de TI e o Analista de TI.

\section{Breve histórico das empresas}

A empresa Alfa é uma empresa multinacional orientada para o mercado global em laminados de alumínio. Atualmente, a empresa emprega cerca de 14.000 colaboradores no mundo e no Brasil cerca de 2.100 funcionários. As quatro fábricas do Brasil estão localizadas nos estados de São Paulo, Minas Gerais e Bahia. A empresa estudada localiza-se no estado de São Paulo. É uma empresa do tipo limitada, com capital internacional e faturamento acima de $\mathrm{R} \$ 50$ milhões. 
Já a empresa Beta é uma empresa multinacional que atua no ramo farmacêutico e emprega mundialmente 36.000 funcionários. As três fábricas localizadas no Brasil (02 em São Paulo e 01 no Paraná) geram em torno de 1.050 empregos. A fábrica aonde o questionário foi aplicado, localizada no estado de São Paulo, emprega 200 funcionários. É uma empresa do tipo limitada, com capital internacional e com faturamento acima de R\$ 50 milhões.

A empresa Gama pertence à indústria calçadista. É uma empresa nacional de médio porte e possui uma fábrica localizada no estado de São Paulo. Atualmente emprega 180 funcionários de forma direta. É uma empresa do tipo limitada, com capital inteiramente nacional. O faturamento anual econtra-se na faixa de R 1 milhão até $\mathrm{R} \$ 5$ milhões.

A empresa Delta atua na fabricação e comércio de artigos para escrita, desenho e pintura. Possui três fábricas no Brasil localizadas nos estados de São Paulo, Minas Gerais e Amazonas. Emprega cerca de 2.800 colaboradores nas fábricas do Brasil, sendo que a fábrica analisada possui 1.300 funcionários e localiza-se no estado de São Paulo. É uma empresa de grande porte (multinacional), caracterizada como sociedade anônima, de capital nacional e com faturamento acima de R\$ 50 milhões.

Quanto à empresa Omega, esta também pertence ao setor calçadista. Possui uma fábrica no estado de São Paulo com 300 funcionários e faturamento entre R\$ 5 a R\$ 20 milhões. É uma empresa de médio porte, de capital nacional e do tipo limitada.

A outra empresa pesquisada, aqui nomeada de Lambda, pertence à indústria de eletrodomésticos e tem quatro fábricas no Brasil. A fábrica pesquisada possui aproximadamente 3.000 funcionários e localiza-se no estado do Paraná. Caracteriza-se como uma empresa de grande porte (multinacional), de capital internacional, do tipo sociedade anônima. O faturamento anual encontra-se na faixa acima de R 50 milhões.

A empresa Theta é fabricante de componentes elétricos e eletrônicos. A organização possui uma fábrica no estado de São Paulo e outra no Amazonas. Constitui-se em uma empresa de grande porte, do tipo limitada, de capital nacional e com faturamento acima de R $\$ 50$ milhões. A empresa entrevistada pertence ao estado de São Paulo e emprega 1.100 funcionários.

Por fim, a empresa Sigma pertence ao segmento de metalurgia. No Brasil, a fábrica está instalada no estado de São Paulo, mas possui várias fábricas instaladas em diversos países. A organização como um todo emprega cerca de 90.000 pessoas, no entanto, a empresa na qual o questionário foi aplicado possui 5.000 funcionários. É uma empresa de grande porte (multinacional), do tipo limitada, de capital internacional e com faturamento acima de R\$ 50 milhões. A Tabela 1 aponta uma breve classificação das empresas pesquisadas. 
Tabela 1 - Características das empresas

\begin{tabular}{|c|c|c|c|c|c|c|c|c|}
\hline $\begin{array}{c}\text { Empresas/ } \\
\text { Características }\end{array}$ & Alfa & Beta & Gama & Delta & Omega & Lambda & Theta & Sigma \\
\hline (a) Porte & $\begin{array}{c}\text { Grande } \\
\text { (multinacional) }\end{array}$ & $\begin{array}{c}\text { Grande } \\
\text { (multinacional) }\end{array}$ & $\begin{array}{c}\text { Médio } \\
\text { (nacional) }\end{array}$ & $\begin{array}{c}\text { Grande } \\
\text { (multinacional) }\end{array}$ & $\begin{array}{c}\text { Médio } \\
\text { (nacional) }\end{array}$ & $\begin{array}{c}\text { Grande } \\
\text { (multinacional) }\end{array}$ & $\begin{array}{c}\text { Grande } \\
\text { (nacional) }\end{array}$ & $\begin{array}{c}\text { Grande } \\
\text { (multinacional) }\end{array}$ \\
\hline (b) Segmento & $\begin{array}{c}\text { Laminados de } \\
\text { Aluminio }\end{array}$ & Farmacêutico & Calçadista & $\begin{array}{l}\text { Artigos de } \\
\text { escrita, desenho } \\
\text { e pintura }\end{array}$ & Calçadista & $\begin{array}{l}\text { Eletrodomés- } \\
\text { ticos }\end{array}$ & $\begin{array}{l}\text { Componentes } \\
\text { elétricos e } \\
\text { eletrônicos }\end{array}$ & Metalúrgica \\
\hline $\begin{array}{l}\text { (c) } \\
\text { Faturamento }\end{array}$ & $\begin{array}{l}\text { Acima de RS } \\
50 \text { milhões }\end{array}$ & $\begin{array}{c}\text { Acima de } R \$ \\
50 \text { milhões }\end{array}$ & $\begin{array}{c}\text { De R\$ } 1 \\
\text { milhão até RS } \\
5 \text { milhões }\end{array}$ & $\begin{array}{c}\text { Acima de R\$ } 50 \\
\text { milhões }\end{array}$ & $\begin{array}{c}\text { De R\$ } 5 \\
\text { milhões até } \\
\text { R\$ } 20 \\
\text { milhões }\end{array}$ & $\begin{array}{c}\text { Acima de R\$ } 50 \\
\text { milhões }\end{array}$ & $\begin{array}{c}\text { Acima de } R S \\
50 \text { milhões }\end{array}$ & $\begin{array}{c}\text { Acima de R\$ } 50 \\
\text { milhões }\end{array}$ \\
\hline
\end{tabular}

Fonte: Dados da Pesquisa

\section{OLAP nas empresas pesquisadas}

Nesta seção, as informações adquiridas foram agrupadas em três subseções. Na subseção 5.1 são apresentadas informações voltadas ao processo decisório, como os motivos para a adoção do OLAP, as melhorias proporcionadas no processo decisório, entre outras. $\mathrm{Na}$ subseção 5.2 são apontadas informações relativas a implantação, como as fontes de dados para o OLAP, itens orçados para implantação, envolvidos no processo de implantação, etc. Por fim, na subseção 5.3 são mostrados em quais níveis da hierarquia estratégica as informações adquiridas por meio do OLAP apóiam a formulação de estratégias.

\subsection{OLAP e processo decisório}

A Tabela 2 apresenta a reunião dos principais dados tratados nesta subseção. Como pode ser observado, dentre as empresas pesquisadas, verificou-se que todas adquiriram conhecimento sobre o OLAP mediante empresas especializadas. Além dessa fonte de informação, a empresa Theta obteve os primeiros contatos com essa ferramenta de apoio à decisão por meio de eventos. Já na empresa Sigma, dentre as fontes consultadas estavam a Internet, o acompanhamento de mercado, e a participação em grupos de TI.

Quando questionado sobre os motivos para adoção do OLAP, verificou-se que a maioria das respostas foi vinculada ao fato de os relatórios padrões utilizados nas empresas possuírem informações insuficientes, o que prejudicava a agilidade e a qualidade na tomada de decisões. Apenas a empresa Omega citou que adotou esta ferramenta de business intelligence devido à troca do ERP (Enterprise Resource Planning) utilizado, sendo que o OLAP estava incluso no projeto do novo ERP implantado.

Dentre as unidades empresariais (setores/departamentos) beneficiadas com o uso das informações cedidas pelo OLAP, sete empresas citaram a área Comercial (Vendas). Houve, também, quatro citações para a área de Finanças e duas citações para as áreas de Marketing, Produção, e Compras. Salienta-se que houve aplicação do OLAP, ainda, nas áreas de Supply Chain, 
Logística, Recursos Humanos, Contabilidade, Custo do produto, Controladoria, e Desenvolvimento do Produto, com uma citação para cada área. Portanto, nota-se que as áreas empresariais aonde o OLAP é mais utilizado são as seguintes: Comercial (Vendas) e Financeira.

Tabela 2 - Dados gerais sobre as organizações pesquisadas

\begin{tabular}{|c|c|c|c|c|c|c|c|c|}
\hline $\begin{array}{c}\text { Empresas / } \\
\text { Características }\end{array}$ & Alfa & Beta & Gama & Delta & Omega & Lambda & Theta & Sigma \\
\hline $\begin{array}{l}\text { (d) Motivos } \\
\text { para adoção }\end{array}$ & $\begin{array}{l}\text { Necessidade } \\
\text { de novas } \\
\text { visões } \\
\text { gerenciais e } \\
\text { análises }\end{array}$ & $\begin{array}{l}\text { Agilidade no } \\
\text { processo de } \\
\text { tomada de } \\
\text { decisão }\end{array}$ & $\begin{array}{c}\text { Facilidade } \\
\text { para utilizar } \\
\text { os dados para } \\
\text { toma de } \\
\text { decisões }\end{array}$ & $\begin{array}{c}\text { Agilizar } \\
\text { processo } \\
\text { decisório; } \\
\text { independên- } \\
\text { cia na } \\
\text { aquisição de } \\
\text { dados }\end{array}$ & $\begin{array}{l}\text { Troca do } \\
\text { ERP }\end{array}$ & $\begin{array}{l}\text { Necessidade de } \\
\text { gerar } \\
\text { indicadores } \\
\text { estratégicos } \\
\text { com grande } \\
\text { volume de } \\
\text { dados }\end{array}$ & $\begin{array}{l}\text { Flexibilidade e } \\
\text { rapidez na } \\
\text { obtenção de } \\
\text { informações }\end{array}$ & $\begin{array}{c}\text { Informação } \\
\text { padronizada, } \\
\text { centralizada, } \\
\text { facilidade para } \\
\text { tomada de } \\
\text { decisão, } \\
\text { acurácia, } \\
\text { desempenho }\end{array}$ \\
\hline $\begin{array}{l}\text { (e) Decisões } \\
\text { antes do } \\
\text { OLAP }\end{array}$ & $\begin{array}{l}\text { Relatórios de } \\
\text { sistema } \\
\text { relacionais } \\
\text { consolidados } \\
\text { em planilhas } \\
\text { Excel }\end{array}$ & $\begin{array}{l}\text { Relatórios } \\
\text { extraídos no } \\
\text { operacional }\end{array}$ & $\begin{array}{l}\text { Relatórios } \\
\text { emitidos no } \\
\text { ERP }\end{array}$ & $\begin{array}{l}\text { Relatórios } \\
\text { padrões }\end{array}$ & $\begin{array}{l}\text { Relatórios } \\
\text { padrões }\end{array}$ & $\begin{array}{l}\text { Aplicações em } \\
\text { banco de dados } \\
\text { relacional; } \\
\text { consolidação de } \\
\text { planilhas } \\
\text { eletrônicas }\end{array}$ & $\begin{array}{l}\text { Relatórios do } \\
\text { ERP ou do } \\
\text { Excel } \\
\text { adequados a } \\
\text { necessidade }\end{array}$ & $\begin{array}{c}\text { Aplicação } \\
\text { desenvolvida } \\
\text { em Access com } \\
\text { consulta à base } \\
\text { de dados } \\
\text { transacional }\end{array}$ \\
\hline $\begin{array}{l}\text { (f) Decisor (es) } \\
\text { pela } \\
\text { implantação }\end{array}$ & $\begin{array}{c}\text { Gerente e } \\
\text { Analista de } \\
\text { sistemas }\end{array}$ & $\begin{array}{l}\text { Gerente de } \\
\text { sistemas de } \\
\text { informação }\end{array}$ & $\begin{array}{c}\text { Gerente de TI } \\
\text { e Diretoria }\end{array}$ & $\begin{array}{l}\text { Diretores e } \\
\text { Gerentes de } \\
\text { alto escalão }\end{array}$ & Diretoria & $\begin{array}{c}\text { Gerente de } \\
\text { divisão de TI }\end{array}$ & $\begin{array}{c}\text { Gerência de alto } \\
\text { escalão com } \\
\text { área de TI }\end{array}$ & $\begin{array}{l}\text { Diretoria e } \\
\text { Gerência }\end{array}$ \\
\hline $\begin{array}{l}\text { (g) } \\
\text { Dificuldades } \\
\text { de } \\
\text { implantação }\end{array}$ & $\begin{array}{l}\text { Resistência a } \\
\text { mudanças, } \\
\text { unificar a base } \\
\text { de dados, } \\
\text { corrigir ou } \\
\text { complementar } \\
\text { dado na } \\
\text { origem }\end{array}$ & $\begin{array}{c}\text { Falta de } \\
\text { qualidade dos } \\
\text { dados de } \\
\text { origem, } \\
\text { descomprometi- } \\
\text { mento dos } \\
\text { usuários, } \\
\text { infraestrutura }\end{array}$ & $\begin{array}{c}\text { Não } \\
\text { informado }\end{array}$ & $\begin{array}{c}\text { Mapear } \\
\text { origem das } \\
\text { informações; } \\
\text { Gerar } \\
\text { interfaces dos } \\
\text { sistemas }\end{array}$ & $\begin{array}{l}\text { Resistência } \\
\text { a mudanças }\end{array}$ & $\begin{array}{l}\text { Resistência a } \\
\text { mudanças, } \\
\text { granularidade } \\
\text { de informações, } \\
\text { várias fontes de } \\
\text { dados }\end{array}$ & $\begin{array}{l}\text { Resistência a } \\
\text { mudanças; } \\
\text { correção da base } \\
\text { de dados }\end{array}$ & $\begin{array}{l}\text { Falta de dados, } \\
\text { diversas fontes } \\
\text { de dados sem } \\
\text { relacionamento }\end{array}$ \\
\hline $\begin{array}{l}\text { (h) Unidades } \\
\text { beneficiadas }\end{array}$ & $\begin{array}{l}\text { Financeiro, } \\
\text { Controladoria, } \\
\text { Comercial e } \\
\text { Marketing }\end{array}$ & $\begin{array}{l}\text { Financeiro, } \\
\text { Marketing, } \\
\text { Comercial, } \\
\text { Manufatura } \\
\text { e Compras }\end{array}$ & $\begin{array}{c}\text { Vendas } \\
\text { (Comercial), } \\
\text { Compras e } \\
\text { Desenvolvi- } \\
\text { mento de } \\
\text { produtos }\end{array}$ & Comercial & $\begin{array}{c}\text { Vendas } \\
\text { (Comercial) }\end{array}$ & $\begin{array}{l}\text { Comercial, } \\
\text { Administrativo- } \\
\text { financeira, } \\
\text { Supply Chain }\end{array}$ & $\begin{array}{l}\text { Recursos } \\
\text { Humanos, } \\
\text { Financeiro, } \\
\text { Comercial, } \\
\text { Logística, } \\
\text { Manufatura }\end{array}$ & $\begin{array}{c}\text { Área de } \\
\text { Negócio, } \\
\text { especificamente } \\
\text { Contabilidade/ } \\
\text { Custo do } \\
\text { Produto }\end{array}$ \\
\hline $\begin{array}{l}\text { (i) Melhorias } \\
\text { no processo } \\
\text { decisório }\end{array}$ & $\begin{array}{l}\text { Informação } \\
\text { única, } \\
\text { confiável, } \\
\text { disponível em } \\
\text { ambiente } \\
\text { compartilhado } \\
\text { e de fácil } \\
\text { manuseio }\end{array}$ & $\begin{array}{l}\text { Agilidade na } \\
\text { tomada de } \\
\text { decisão }\end{array}$ & $\begin{array}{l}\text { Agilidade e } \\
\text { flexibilidade } \\
\text { na } \\
\text { manipulação } \\
\text { dos dados }\end{array}$ & $\begin{array}{c}\text { Agilidade e } \\
\text { flexibilidade } \\
\text { na } \\
\text { manipulação } \\
\text { dos dados e } \\
\text { no processo } \\
\text { decisório }\end{array}$ & $\begin{array}{c}\text { Agilidade } \\
\text { na obtenção } \\
\text { de dados e } \\
\text { não } \\
\text { necessidade } \\
\text { de um } \\
\text { programa- } \\
\text { dor }\end{array}$ & $\begin{array}{l}\text { Agilidade na } \\
\text { obtenção de } \\
\text { dados e } \\
\text { centralização } \\
\text { de informações } \\
\text { gerenciais }\end{array}$ & $\begin{array}{l}\text { Rapidez e } \\
\text { flexibilidade na } \\
\text { obtenção de } \\
\text { dados }\end{array}$ & $\begin{array}{l}\text { Agilidade na } \\
\text { tomada de } \\
\text { decisão, } \\
\text { informação } \\
\text { consistente com } \\
\text { acurácia }\end{array}$ \\
\hline $\begin{array}{l}\text { (j) Interesse } \\
\text { em outras } \\
\text { ferramentas de } \\
\text { Apoio à } \\
\text { Decisão }\end{array}$ & $\begin{array}{l}\text { Sim/Planning, } \\
\text { melhorias no } \\
\text { Metric } \\
\text { Manager, } \\
\text { Dash Board }\end{array}$ & $\begin{array}{c}\mathrm{Sim} / \\
\text { Em análise }\end{array}$ & Não & Não & $\begin{array}{c}\text { Sim/ } \\
\text { ampliar o } \\
\text { uso do } \\
\text { OLAP atual }\end{array}$ & $\begin{array}{l}\text { Sim/Novas } \\
\text { versões de } \\
\text { OLAP e Portal } \\
\text { Corporativo }\end{array}$ & $\begin{array}{c}\mathrm{Sim} / \\
\text { Em análise }\end{array}$ & $\begin{array}{c}\text { Sim/ ampliar o } \\
\text { uso do OLAP } \\
\text { atual }\end{array}$ \\
\hline
\end{tabular}

Fonte: Dados da pesquisa

Além das unidades beneficiadas, foi questionado sobre os usuários do OLAP na empresa. A empresa Omega explicitou que apenas o Gerente comercial utiliza esta ferramenta de apoio à decisão, e na empresa Sigma, somente o analista financeiro usa o OLAP. As demais empresas afirmaram que os funcionários que necessitassem de informações contidas no OLAP poderiam consultá-lo, não restringindo o acesso a esta ferramenta.

A manutenção do OLAP nas empresas Alfa, Beta, Delta e Theta é feita pelos analistas de sistemas vinculados as organizações, sendo que a empresa Gama atribuiu tal tarefa ao departamento de informática. A empresa Lambda preferiu terceirizar tal atividade a uma empresa contratada. As empresas Omega e Sigma preferiram não informar tal ponto questionado. 
Os usuários do OLAP obtiveram as seguintes percepções de melhoria do processo decisório: informação única, centralizada, confiável, consistente, disponível em ambiente compartilhado de fácil manuseio, agilidade na tomada de decisão, rapidez e flexibilidade na manipulação/obtenção de dados e no processo decisório, e não necessidade de um programador para obter informações. A maior freqüência de respostas foi para agilização do processo decisório, seguido da flexibilidade de manipulação dos dados.

Quando questionado sobre alterações no quadro de funcionários após a adoção do OLAP, somente a empresa Lambda alegou que houve contratação. Todas as outras empresas informaram que os respectivos quadros de funcionários mantiveram-se iguais.

Verificou-se, também, que os decisores pela implantação do OLAP estão relacionados com a área de TI em cinco das oito empresas entrevistadas, como pode ser visto na Tabela 2. Este fato apóia a tendência assinalada na revista Info Corporate (2004): os CIO's (Chief Information Officer) passam a ter maior poder decisório nas corporações, com atribuição de responsabilidade sobre toda a organização.

Questionou-se, ainda, sobre as dificuldades enfrentadas para implantação do OLAP nas empresas. Foram identificadas as seguintes dificuldades: i) Resistência a mudanças por parte dos usuários; ii) Unificação da base de dados; iii) Correção/complementação do dado de origem; iv) Infraestrutura inadequada; v) Geração de interfaces dos sistemas; vi) Granularidade de informações; vii) Mapeamento da origem das informações; viii) Falta de qualidade dos dados de origem. Deste modo, das empresas respondentes, a maioria das citações foi vinculada a dificuldade em garantir a qualidade dos dados para gerar informações precisas, que é uma das principais preocupações quando há a necessidade de unificar a base de dados da organização. Outra dificuldade muito citada foi a resistência a mudanças por parte dos usuários. A empresa Omega manifestou que alguns usuários não queriam aprender a utilizar a nova ferramenta de apoio à decisão, preferindo utilizar somente os relatórios padrões fornecidos pelo ERP.

Seis empresas expuseram que possuem interesse em novas ferramentas de apoio à decisão. As novas ferramentas expostas foram o Dash Board, o Planning, o Portal Corporativo, e novas versões do OLAP. Algumas empresas informaram o interesse em ampliar o uso do OLAP atual e também realizar melhorias no Metric Manager implantado. As empresas Beta e Theta, no momento da entrevista, ainda estavam analisando quais ferramentas seriam interessantes para implantação.

\subsection{OLAP e aspectos de implantação}

A empresa Gama foi a primeira a implantar o OLAP, quando comparada com as demais empresas entrevistadas (vide Tabela 3). Os maiores tempos de implantação desta ferramenta de 
apoio à decisão foram das empresas Beta e Theta (1 ano), e o menor tempo de implantação foi da empresa Delta (3 meses). Ademais, 50\% das empresas expuseram que o cronograma de implantação não foi plenamente executado, atingindo um tempo superior ao planejado.

Tabela 3 - Aspectos estruturais

\begin{tabular}{|c|c|c|c|c|c|c|c|c|}
\hline $\begin{array}{c}\text { Empresas / } \\
\text { Características }\end{array}$ & Alfa & Beta & Gama & Delta & Omega & Lambda & Theta & Sigma \\
\hline $\begin{array}{l}\text { (k) Ano/tempo } \\
\text { de } \\
\text { implantação }\end{array}$ & $\begin{array}{c}2003 / \\
6 \text { meses }\end{array}$ & $\begin{array}{l}2001 / \\
1 \text { ano }\end{array}$ & $\begin{array}{c}2000 / \\
4 \text { meses }\end{array}$ & $\begin{array}{c}2005 / \\
3 \text { meses }\end{array}$ & $\begin{array}{c}2003 / \\
4 \text { meses }\end{array}$ & $\begin{array}{c}2001 / \\
6 \text { meses }\end{array}$ & $\begin{array}{l}2005 / \\
1 \text { ano }\end{array}$ & $\begin{array}{c}2005 / \\
8 \text { meses }\end{array}$ \\
\hline $\begin{array}{l}\text { (l) Fornecedor } \\
\text { do OLAP }\end{array}$ & $\begin{array}{c}\text { Empresa } \\
\text { especializada/ } \\
\text { Cognos/ } \\
\text { Uniplace }\end{array}$ & $\begin{array}{c}\text { Empresa } \\
\text { especializada/ } \\
\text { não } \\
\text { informado }\end{array}$ & $\begin{array}{c}\text { Empresa } \\
\text { especializa- } \\
\text { da/ CHB } \\
\text { Informática }\end{array}$ & $\begin{array}{c}\text { Empresa } \\
\text { especializada/ } \\
\text { Execplan }\end{array}$ & $\begin{array}{c}\text { Empresa } \\
\text { especializada/ } \\
\mathrm{CHB} \\
\text { Informática }\end{array}$ & $\begin{array}{c}\text { Empresa } \\
\text { especializada/ } \\
\text { eSat } \\
\text { Consultoria e } \\
\text { Sistemas }\end{array}$ & $\begin{array}{c}\text { Empresa } \\
\text { especializada/ } \\
\text { Datasul }\end{array}$ & $\begin{array}{c}\text { Empresa } \\
\text { especializada/ } \\
\text { Cognos }\end{array}$ \\
\hline $\begin{array}{l}\text { (m) OLAP } \\
\text { nativo do ERP/ } \\
\text { fornecedor } \\
\text { ERP }\end{array}$ & $\begin{array}{l}\text { Não/Oracle } \\
\text { Aplication }\end{array}$ & Não/BPCS & $\begin{array}{c}\text { Não } \\
\text { informado }\end{array}$ & Não/SAP & $\mathrm{Sim} / \mathrm{CHB}$ & $\begin{array}{c}\text { Não/ } \\
\text { ORACLE } \\
\text { (Peoplesoft) }\end{array}$ & Não/Datasul & $\begin{array}{l}\text { Não/Local, } \\
\text { Peoplesoft, } \\
\text { SAP }\end{array}$ \\
\hline $\begin{array}{l}\text { (n) Itens } \\
\text { orçados para } \\
\text { implantação }\end{array}$ & $\begin{array}{l}\text { Software, } \\
\text { licença de uso, } \\
\text { consultoria, } \\
\text { infra-estrutura, } \\
\text { treinamento }\end{array}$ & $\begin{array}{c}\text { Não } \\
\text { informado }\end{array}$ & $\begin{array}{c}\text { Licença de } \\
\text { uso e } \\
\text { desenvolvi- } \\
\text { mento da } \\
\text { ferramenta } \\
\text { (R\$ } 30 \text { mil) }\end{array}$ & $\begin{array}{l}\text { Software, } \\
\text { hardware, } \\
\text { consultoria, } \\
\text { implantação, } \\
\text { treinamento }\end{array}$ & $\begin{array}{l}\text { Licença de } \\
\text { uso, } \\
\text { mensalidade, } \\
\text { facilidade de } \\
\text { uso, infra- } \\
\text { estrutura }\end{array}$ & $\begin{array}{l}\text { Consultoria } \\
\text { (R\$ } 300 \text { mil); } \\
\text { infra-estrutura } \\
\quad(150 \text { mil })\end{array}$ & $\begin{array}{c}\text { Software } \\
\text { (R\$ } 80 \text { mil), } \\
\text { Manutenção } \\
\text { (R\$ 2,5 mil), } \\
\text { Treinamento } \\
\text { (R\$10 mil), } \\
\text { consultoria } \\
\text { (R\$30 mil) }\end{array}$ & $\begin{array}{l}\text { Licença de } \\
\text { uso de } \\
\text { software, } \\
\text { treinamento, } \\
\text { consultoria }\end{array}$ \\
\hline $\begin{array}{l}\text { (o) Fonte de } \\
\text { dados }\end{array}$ & $\begin{array}{c}\text { ERP, Excel e } \\
\text { Sistemas } \\
\text { legados }\end{array}$ & $\begin{array}{c}\text { ERP e } \\
\text { Sistemas } \\
\text { legados }\end{array}$ & ERP & $\begin{array}{c}\text { ERP e Sistemas } \\
\text { legados }\end{array}$ & ERP & $\begin{array}{c}\text { ERP, Excel, } \\
\text { Access, SQL } \\
\text { Server, Oracle }\end{array}$ & ERP & ERP \\
\hline $\begin{array}{l}\text { (p) Fatos/ } \\
\text { Dimensões }\end{array}$ & $\begin{array}{l}\text { Faturamento } \\
\text { comercial, } \\
\text { etc./Margem de } \\
\text { venda, receita } \\
\text { líquida, etc. }\end{array}$ & $\begin{array}{c}\text { Não } \\
\text { informado/ } \\
150 \\
\text { relaciona- } \\
\text { mentos } \\
\text { possíveis }\end{array}$ & $\begin{array}{l}\text { Quantidade } \\
\text { de pares, } \\
\text { preço, } \\
\text { consumo de } \\
\text { materiais/ } \\
\text { Representan- } \\
\text { te, cliente, } \\
\text { modelos, } \\
\text { linhas de } \\
\text { produção }\end{array}$ & $\begin{array}{c}\text { Não informado/ } \\
25 \text { dimensões } \\
\text { com } 300 \\
\text { variáveis }\end{array}$ & $\begin{array}{l}\text { Vendas/ } \\
\text { região, linha, } \\
\text { modelo, } \\
\text { representante, } \\
\text { etc. }\end{array}$ & $\begin{array}{l}\text { Vendas, } \\
\text { Planejamento, } \\
\text { Inbound, } \\
\text { etc./Estrutura } \\
\text { comercial, } \\
\text { Geográfica, de } \\
\text { produto, } \\
\text { tempo, etc. }\end{array}$ & $\begin{array}{c}\text { Vendas, } \\
\text { despesas, } \\
\text { receitas, } \\
\text { custos/vendas } \\
\text { por cliente, } \\
\text { atendimento } \\
\text { de } \\
\text { fornecedores, } \\
\text { etc. }\end{array}$ & $\begin{array}{l}\text { Custo do } \\
\text { produto, } \\
\text { compra de } \\
\text { materiais/ } \\
\text { tempo, } \\
\text { produto, item, } \\
\text { fornecedor, } \\
\text { etc. }\end{array}$ \\
\hline $\begin{array}{l}\text { (q) Envolvidos } \\
\text { no processo de } \\
\text { implantação }\end{array}$ & $\begin{array}{c}\text { Gerente e } \\
\text { Analista de } \\
\text { sistemas / } \\
\text { Gerente e } \\
\text { Analista de } \\
\text { Controladoria }\end{array}$ & $\begin{array}{l}\text { Gerentes, } \\
\text { Analistas e } \\
\text { Usuários }\end{array}$ & $\begin{array}{l}\text { Gerente de } \\
\text { TI, Diretor } \\
\text { Comercial e } \\
\text { Diretor de } \\
\text { Compras }\end{array}$ & $\begin{array}{c}\text { Diretores, } \\
\text { Gerentes, } \\
\text { Chefes de } \\
\text { departamentos e } \\
\text { alguns usuários } \\
\text { chaves }\end{array}$ & $\begin{array}{l}\text { Funcionários } \\
\text { dos setores } \\
\text { administrativo } \\
\text { e comercial }\end{array}$ & $\begin{array}{l}\text { Gerente de TI, } \\
\text { Gerente de } \\
\text { sistema, } \\
\text { Gerente } \\
\text { Administrativo } \\
\text { Comercial, } \\
\text { Gerente de } \\
\text { Negócios }\end{array}$ & $\begin{array}{l}\text { Gerência e } \\
\text { Analistas de } \\
\text { sistemas }\end{array}$ & $\begin{array}{l}\text { Diretoria, } \\
\text { Gerência, } \\
\text { Supervisão, } \\
\text { Analistas e } \\
\text { Técnicos }\end{array}$ \\
\hline $\begin{array}{l}\text { (r) Execução } \\
\text { do orçado/ } \\
\text { Execução do } \\
\text { cronograma }\end{array}$ & $\begin{array}{l}\text { Não informado/ } \\
\operatorname{sim}\end{array}$ & $\begin{array}{c}\text { Não } \\
\text { informado/ } \\
\text { não }\end{array}$ & $\mathrm{Sim} / \mathrm{sim}$ & $\begin{array}{l}\text { Não(acima)/ } \\
\text { não (acima) }\end{array}$ & $\mathrm{Sim} / \mathrm{Sim}$ & $\begin{array}{l}\text { Não (acima)/ } \\
\text { sim }\end{array}$ & $\begin{array}{l}\text { Sim (abaixo- } \\
\text { R\$ } 110 \text { mil)/ } \\
\text { não (acima) }\end{array}$ & $\begin{array}{l}\text { Sim (abaixo - } \\
80 \% \text { do valor } \\
\text { orçado)/ não } \\
\text { (acima) }\end{array}$ \\
\hline
\end{tabular}

Fonte: Dados da pesquisa

Os fornecedores do OLAP para todas as empresas estudadas foram empresas especializadas no ramo de TI, dentre elas a Uniplace, Cognos, CHB Informática, Execplan, eSat Consultoria e Sistemas, e a Datasul.

Identificou-se, ainda, que o OLAP não era nativo ao ERP da empresa em seis das sete empresas que responderam esta questão. Dentre os fornecedores de ERP dos respondentes estão a ORACLE, a SAP, a Datasul, a CHB Informática, e a BPCS.

Dentre os itens orçados para implantação do OLAP, estão: i) infraestrutura; ii) licença de uso; iii) consultoria/implantação; iv) treinamento; v) desenvolvimento da ferramenta; vi) manutenção. Além dos itens orçados, algumas empresas explicitaram o valor orçado em cada item, 
como o exemplo da empresa Lambda que orçou R\$ 450 mil, distribuídos em consultoria (R $\$ 300$ mil) e infraestrutura (R\$ $150 \mathrm{mil})$, como pode ser observado na Tabela 3. Ainda foi identificado que, das seis empresas que responderam sobre a execução do valor orçado, quatro alegaram que o valor final não excedeu o orçado, sendo que a empresa Theta afirmou que dos R $\$ 122,5$ mil orçados foram gastos aproximadamente R 110 mil, e na empresa Sigma houve uma economia de 20\% do valor total orçado.

Verificou-se que todas as empresas pesquisadas possuem o ERP como a principal fonte de dados para o OLAP. Além disso, nas empresas Alfa, Beta, Delta e Lambda há também a utilização de sistemas legados. As empresas Gama, Omega, Theta e Sigma utilizam exclusivamente o ERP como fonte de dados.

Algumas das empresas pesquisadas informaram alguns fatos (ocorrências que têm importância para a tomada de decisão) e dimensões (formam as linhas e as colunas da matriz) presentes no OLAP em que utilizam. Dentre os fatos explicitados estão as vendas, as despesas, os custos dos produtos, a compra de materiais, preço, quantidade de pares, consumo de materiais, e o faturamento comercial. Quanto as dimensões, estão a margem de venda, a receita líquida, linhas de produção, modelos, vendas por clientes, entre outros. A empresa Beta afirmou que o OLAP implantado possui cerca de 150 relacionamentos possíveis e a empresa Delta alegou que o OLAP implantado possui 25 dimensões com 300 variáveis.

Também foi questionado sobre os funcionários envolvidos no processo de implantação do OLAP nas empresas. Verificou-se que a empresa Omega não envolveu funcionários próprios da área de TI no processo de implantação e a empresa Theta não envolveu os futuros usuários do OLAP durante a implantação. As demais empresas englobaram, pelo menos, usuários chaves dos setores/departamentos beneficiados na implantação da ferramenta de apoio à decisão.

\subsection{OLAP e formulação de estratégias}

Todas as empresas alegaram que as informações obtidas com o uso do OLAP auxiliam na elaboração de estratégias em pelo menos um dos níveis hierárquicos, como pode ser visto na Tabela 4. As empresas Alfa, Beta e Lambda afirmaram que essas informações beneficiam a formulação de estratégias corporativas, de unidades de negócio, e funcionais. As empresas Gama e Sigma afirmaram que essas informações apóiam apenas a elaboração de estratégias funcionais. No entanto, para as empresas Omega e Theta, somente a formulação de estratégias corporativas é beneficiada com as informações do OLAP.

Dentre as empresas entrevistadas, apenas as empresas Gama e Omega não realizam o processo formal de planejamento estratégico, mas estas afirmaram que, mesmo assim, há a 
definição de estratégias. Salienta-se que na maioria das empresas em que o planejamento estratégico é realizado formalmente, este processo é conduzido pela diretoria e/ou gerência de alto escalão. A empresa Lambda reforçou que há, também, a participação dos gerentes de negócio da área de TI.

Verificou-se, ainda, que sete das oito empresas pesquisadas utilizam indicadores de desempenho com o OLAP. Somente a empresa Omega não utiliza o OLAP com tal finalidade.

Tabela 4 - Auxílio do OLAP para formulação de estratégias

\begin{tabular}{|c|c|c|c|c|c|c|c|c|}
\hline $\begin{array}{c}\text { Empresas / } \\
\text { Características }\end{array}$ & Alfa & Beta & Gama & Delta & Omega & Lambda & Theta & Sigma \\
\hline $\begin{array}{l}\text { (s) Tipos de } \\
\text { estratégias } \\
\text { beneficiadas }\end{array}$ & $\begin{array}{l}\text { Corporativas, } \\
\text { Unidades de } \\
\text { negócio e } \\
\text { Funcionais }\end{array}$ & $\begin{array}{l}\text { Corporativas, } \\
\text { Unidades de } \\
\text { negócio e } \\
\text { Funcionais }\end{array}$ & Funcionais & $\begin{array}{l}\text { Unidades de } \\
\text { negócio e } \\
\text { Funcionais }\end{array}$ & Corporativas & $\begin{array}{l}\text { Corporativas, } \\
\text { Unidades de } \\
\text { negócio e } \\
\text { Funcionais }\end{array}$ & Corporativas & Funcionais \\
\hline $\begin{array}{l}\text { (t) Realização de } \\
\text { planejamento } \\
\text { estratégico }\end{array}$ & Sim & Sim & Não & Sim & Não & Sim & Sim & Sim \\
\hline $\begin{array}{l}\text { (u) Participantes } \\
\text { do planejamento } \\
\text { estratégico }\end{array}$ & $\begin{array}{l}\text { Diretores da } \\
\text { companhia }\end{array}$ & $\begin{array}{c}\text { Diretores e } \\
\text { Gerentes de alto } \\
\text { escalão }\end{array}$ & - & $\begin{array}{l}\text { Diretores e } \\
\text { Gerentes de } \\
\text { alto escalão }\end{array}$ & - & $\begin{array}{c}\text { Gerente de } \\
\text { divisão e os } \\
\text { Gerentes de } \\
\text { negócio da área } \\
\text { de TI }\end{array}$ & $\begin{array}{l}\text { Diretores e } \\
\text { Gerentes de } \\
\text { alto escalão }\end{array}$ & $\begin{array}{c}\text { Diretores e } \\
\text { Gerentes } \\
\text { de alto } \\
\text { escalão }\end{array}$ \\
\hline $\begin{array}{l}\text { (v) Uso de } \\
\text { indicadores de } \\
\text { desempenho }\end{array}$ & Sim & Sim & Sim & Sim & Não & Sim & Sim & Sim \\
\hline
\end{tabular}

Foi questionado, também, sobre a utilização das características de análise OLAP. Esta questão aponta as maneiras como as empresas entrevistadas organizam os dados para obter informações a respeito dos indicadores de desempenho. As características de análise são: Drill Across (pular um nível intermediário dentro de uma mesma dimensão), Drill Down (aumentar o nível de detalhe da informação), Drill UP (diminuir o nível de detalhamento da informação), Drill Throught (passar de uma informação contida em uma dimensão para uma outra), Ranking (agrupar resultados por ordem de maiores e menores), Sorts (ordenar uma informação), Filtros (filtrar os dados recuperados pelo usuário), Alertas (destacar valores mediante condições), Slice and Dice (alterar linhas por colunas, modificar a posição de uma informação, recuperar o microcubo dentro do OLAP e girar o cubo sempre que houver a necessidade) e Breaks (separar o relatório em grupos/blocos de informações).

Verificou-se que $87,5 \%$, ou seja, sete das oito empresas entrevistadas utilizam Drill Across, Drill Down, Drill UP, Drill Throught, Ranking e Sorts. Além dessas formas de análise, 100\% das empresas usam Filtros; 62,5\% das empresas utilizam, também, Alertas e Slice and Dice; e 50\% das empresas utilizam Breaks, como pode ser visto na Figura 1. Cabe ressaltar que a empresa Alfa emprega todas as características de análise aqui apresentadas. A empresa Theta é a que menos utiliza o potencial de análise do OLAP, valendo-se apenas de 50,0\% dessas formas de análise. 
Figura 1 - Características de análise OLAP

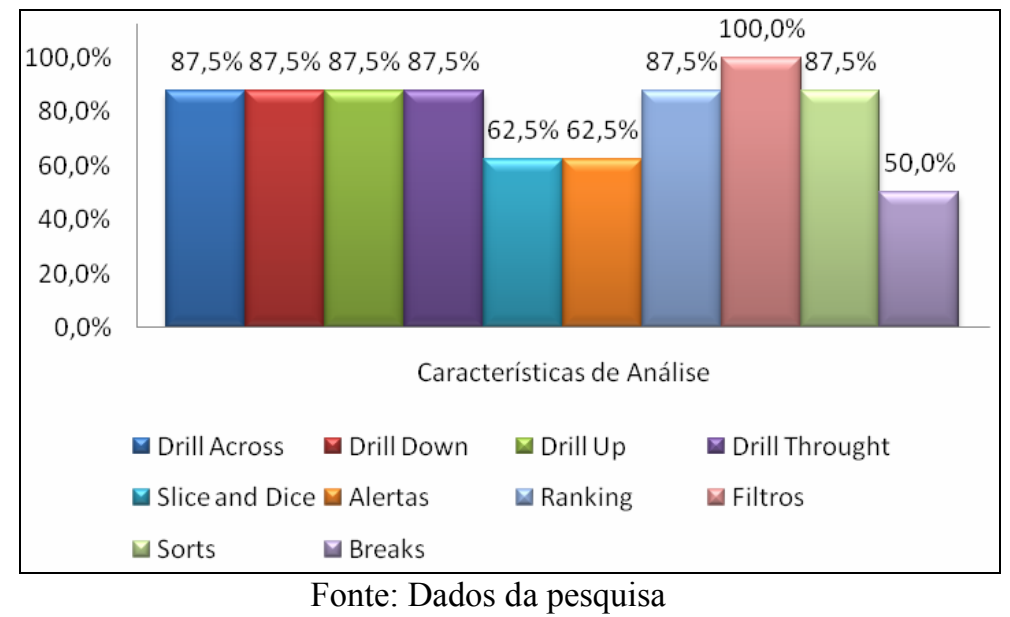

\section{Análise dos casos}

A Tabela 2, apresentada na subseção 5.1, mostra aspectos organizacionais relevantes sobre as empresas Alfa, Beta, Gama, Delta, Omega, Lambda, Theta e Sigma nos períodos de préimplantação, de implantação e pós-implantação.

Ressalta-se que a linha 'f' da Tabela 2 e a linha 'q' da Tabela 3 (subseção 5.2) possuem significados diferentes. A linha 'f' aponta quem tomou a decisão de implantar o OLAP e a linha 'q' indica quem participou do processo de implantação de tal ferramenta.

A partir dos oito casos apresentados na seção anterior, percebe-se que não há ligação entre o porte da empresa e a rápida adoção do OLAP como alternativa importante de melhoria do processo decisório. A empresa Gama, que é de médio porte, implantou primeiro o OLAP comparado às demais organizações estudadas, como pode ser visto nas linhas 'a' da Tabela 1 (seção 4) e ' $k$ ' da Tabela 3. Verifica-se, ainda, que a empresa Omega, que também possui médio porte, implantou esta ferramenta primeiro que as empresas Delta, Theta e Sigma, que são de grande porte.

Nas organizações Alfa, Beta, Gama, Lambda e Theta, os decisores pela implantação do OLAP possuem envolvimento com a área de TI da empresa, englobando também cargos gerenciais dentro desta área. Além disso, há os casos das empresas Gama e Theta que também abrangem a Diretoria no processo decisório de implantação da ferramenta de apoio à decisão. Nas empresas Delta, Omega e Sigma essa decisão foi tomada apenas pela Diretoria e Gerência de alto escalão vide linha ' $f$ ' da Tabela 2.

Nas empresas Beta, Delta e Omega os usuários finais tiveram melhores oportunidades de manifestarem-se durante o processo de implantação, como pode ser observado na linha 'q' da Tabela 3. Durante a entrevista, foi narrado que a utilização do OLAP nessas empresas foi fácil, pois a ferramenta estava adequada às necessidades dos usuários. Portanto, nas empresas Alfa, Gama, 
Lambda, Theta e Sigma houve maior necessidade de treinamento dos usuários para o uso de tal ferramenta de apoio à decisão, como de fato ocorreu.

Há predominância do uso do OLAP nos setores vendas/comercial/marketing das empresas estudadas, como apontado na linha ' $h$ ' da Tabela 2. Cabe ressaltar que os departamentos de vendas das empresas Gama e Omega englobam as funções comercial e marketing e nas empresas Delta, Lambda e Theta o departamento comercial envolve as funções vendas e marketing.

Por meio da análise das linhas 'b' da Tabela 1 e ' $h$ ' da Tabela 2, apenas nas empresas Beta e Gama o setor compras foi mencionado, pois nos respectivos segmentos em que atuam (farmacêutico e calçadista), o acompanhamento dos fornecedores é maior, pela grande diversidade de matériasprimas e demais componentes para fabricar seus produtos. Nas empresas Alfa, Beta, Lambda e Theta o setor financeiro foi comumente beneficiado. Ao analisar as linhas ' $a$ ' $e$ ' $b$ ' da Tabela $1 \mathrm{e}$ ' $h$ ' da Tabela 2, identifica-se maior interesse do uso do OLAP na área financeira, pois provavelmente existe maior número de clientes nestas empresas ao comparar com as demais. Nas empresas Omega e Sigma há intenção de ampliar o uso do OLAP para demais setores como o financeiro.

A empresa Gama também utiliza o OLAP no setor de desenvolvimento de produtos, possivelmente, devido ao fato de o tempo de vida do produto lá fabricado ser curto, em relação às empresas Alfa, Beta, Delta, Lambda e Sigma. Geralmente, no setor calçadista, a cada três meses são lançados novos produtos que substituam os existentes. Assim, há grande massa de dados como, por exemplo, o número de código de produtos. A empresa Beta utiliza também no setor de Manufatura, o que pode ser explicado pela quantidade de máquinas que devem ser utilizadas para a fabricação de produtos farmacêuticos e informações relativas ao processamento nestas máquinas. As empresas Lambda e Theta apresentaram uma novidade de aplicação do OLAP, respectivamente, nas áreas de Supply Chain e Logística, pois sentiram a necessidade de agilizar o processo decisório quanto à movimentação/suprimento de materiais, pessoas e informações.

O ERP constitui a fonte de dados essencial para o processamento analítico on-line dos dados de todas as empresas analisadas, conforme linha 'o' da Tabela 3. O fato de as empresas Alfa, Beta, Delta e Lambda não usarem apenas o ERP como fonte de dados para alimentar o OLAP é plausível, pois estas empresas são de grande porte e o ERP implantado não atende a todas as demandas dos setores beneficiados pelo OLAP. Notou-se a utilização de ferramentas OLAP não nativas ao ERP por empresas de tal porte, o que deve despertar a atenção dos fornecedores de tal sistema. Além disso, nas grandes empresas a passagem dos dados das fontes para o data warehouse deve exigir maior esforço. Quanto as médias empresas que possuem apenas o ERP como fonte de dados, este esforço se traduz em menos operações, menor chance de erros, maior agilidade nestas atividades de comunicação, etc. Assim, nos casos das empresas Gama, Omega, Theta e Sigma, onde há apenas uma fonte de dados a considerar, esta comunicação pode, inclusive, ser feita com maior freqüência. 
Ademais, as principais melhorias no processo decisório citadas pelas empresas (linha 'i' da Tabela 2) foram a agilidade e a flexibilidade na manipulação dos dados, facilitando a tomada de decisão. Salienta-se que, se for possível entender que o termo agilidade da informação engloba a rapidez e a confiabilidade, todas as empresas entrevistadas concordam com este auxílio à tomada de decisões, sendo que a empresa Alfa destaca, também, o compartilhamento de informações. As empresas Gama e Delta evidenciam a possibilidade de efetuar cruzamentos em várias dimensões em relação a um indicador e a empresa Omega salienta que se tornou desnecessário chamar o programador para se obter um novo relatório.

Constatou-se, também, que no geral as informações geradas por meio do OLAP beneficiam predominantemente a elaboração de estratégias funcionais, exceto nas empresas Omega e Theta, que beneficiam apenas o estabelecimento de estratégias corporativas, vide linha 's' da Tabela 4. Vale ressaltar que, para as empresas multinacionais Alfa, Beta e Lambda, o OLAP auxilia os três níveis estratégicos: corporativo, unidades de negócio e funcional.

O fato de os três tipos de estratégias serem beneficiadas com o uso do OLAP nas empresas Alfa, Beta e Lambda, pode ser explicado pela tendência de as empresas de grande porte trabalharem mais com planejamento estratégico, quando comparadas com empresas de menor porte. As empresas Gama e Omega apontaram, respectivamente, a participação do OLAP nas estratégias funcionais e nas estratégias corporativas, apesar de afirmarem que não realizam o planejamento estratégico formalmente - vide linha ' $t$ ' da Tabela 4.

Apesar de as empresas Delta e Sigma serem multinacionais, há apenas o auxílio às estratégias das unidades de negócio e estratégias funcionais na empresa Delta, e somente nas estratégias funcionais na empresa Sigma, pois os sistemas de Business Intelligence das unidades brasileiras não são integrados com as demais unidades. Quando as unidades brasileiras são analisadas separadamente das outras unidades de negócio destas corporações, há suporte na elaboração dos três tipos de estratégias.

\section{Conclusão}

Verificou-se, com a realização da pesquisa, que o OLAP pode ser utilizado como uma alternativa de melhoria do processo de tomada de decisão e, conforme declarado pelas empresas estudadas, o OLAP auxilia na obtenção de informações importantes para a elaboração de estratégias nos diversos níveis da hierarquia estratégica. Portanto, o objetivo do presente artigo foi atingido. Além disso, esta ferramenta possibilita a explicitação de informações que se encontram ocultas em grandes massas de dados, que se tornam mais visíveis quanto mais as empresas tiverem conhecimento sobre a ferramenta, favorecendo a construção de relatórios ad hoc. 
O fato de as empresas de grande porte, de caráter multinacional, como as empresas Alfa, Beta, Delta e Lambda utilizarem diversas fontes de dados para alimentar o OLAP, ou seja, essas organizações utilizam um ERP e outros sistemas legados como fonte para o OLAP, que também não é um módulo nativo do ERP, mostra que a solução OLAP não precisa ser necessariamente do ERP que a empresa já tenha implantado. Outro fato interessante foi o caso da empresa Gama, que apesar de ser de médio porte, adotou tal ferramenta antes que as empresas Alfa, Beta, Delta, Lambda, Theta e Sigma, que são de grande porte.

Este artigo expõe possíveis usos do OLAP na gestão da informação das empresas, por exemplo, para auxiliar na melhoria do processo decisório e para apoiar a elaboração de estratégias nos diversos níveis da hierarquia (corporativo, unidades de negócio e funcional). Tal ferramenta também pode ser utilizada nas empresas com o intuito de melhorar o acompanhamento das ações estabelecidas em planejamentos, permitindo, assim, maior controle dos fatores críticos de sucesso.

Sugere-se, para pesquisas futuras quanto ao tema aqui abordado, a realização de um survey (pesquisa de avaliação) para averiguar o nível e o propósito de utilização de tal ferramenta de apoio à decisão em empresas componentes dos diversos setores da economia brasileira. Há, também, a possibilidade de considerar tal pesquisa em âmbito internacional.

\begin{abstract}
More and more the organizations need quick and trustful informations to expedite the decision processing and thus follow the dynamic environment in which they are inserted. Among business intelligence tools is OLAP (On-Line Analytical Processing), that facilitate the searching for informations. It allows the search for relevant data with a higher speed and visualization into multidimensional perspectives. The aim of this paper is to identify if the adoption of OLAP business intelligence tool could be considered as an alternative for the improvement of the decision process and aid the formulation of corporative, business units and functional strategies. As to the methodology, the present research is characterized for being of a qualitative approach. The used proceeding was a case study, more specifically, a multicase study. Eight companies which used OLAP were interviewed. Among the main results, it was observed that this decision tool support makes improvements in the decision processing and helps in the elaboration of corporative, business units and functionals strategies.
\end{abstract}

Key-words: olap; business intelligence; decision process; strategies formulation.

\title{
Referências
}

BACHEGA, S. J.; GODINHO FILHO, M. Caracterização dos tipos de integração atualmente existentes na literatura de gestão da manufatura. In: XII Simpósio de Engenharia de Produção, 2005, Bauru, SP. Anais... Bauru: Unesp/SIMPEP, nov. 2005. Disponível em: < http://www.simpep.feb.unesp.br/anais/anais_12/copiar.php?arquivo=Bachega_SJ_ Caracterizacao \%20dos\%20ti.pdf >. Acesso em: 03 de jan. de 2009.

BARDIN, L. Análise de conteúdo. Lisboa: Edições 70, 2000.

BRODBECK, A. F.; Rigoni, E. H.; CANEPA, P.C.V. Uma Análise do Nível de Maturidade do Alinhamento Estratégico entre Negócio e Tecnologia de Informação. In: XXXI Encontro da ANPAD, 2001, Rio de Janeiro, RJ. Anais... Rio de Janeiro: EnANPAD, 2007. 1 CD-ROM. 
BRODBECK, A. F.; HOPPEN, N. Alinhamento estratégico entre os planos de negócio e de tecnologia de informação: um modelo operacional para a implementação. In: XXVI Encontro da ANPAD, 2002, Salvador, BA. Anais... Salvador: EnANPAD, 2002. 1 CD-ROM.

BRODBECK, A. F.; HOPPEN, N.; OLIVEIRA, A. dos S.; MAJDENBAUM, A. Alinhamento entre objetivos organizacionais e sistemas de informação: um estudo de múltiplos casos. In: XXVII Encontro da ANPAD, 2003, Atibaia, SP. Anais... Atibaia: EnANPAD, 2003. 1 CD-ROM.

BRYMAN, A. Research methods and organization studies. London: Uniwin Hyman, 1989. 224 p.

CARON-FASAN, M-L.; JANISSEK-MUNIZ, R. Análise de informações de inteligência estratégica antecipativa coletiva: proposição de um método, caso aplicado e experiências. RAUSP. v. 39, n. 3, jul./ ago./ set. 2004.

CARVALHO, D. R. P.; DONAIRE, D.; GASPAR, M. A. Estudo sobre Alinhamento entre Estratégia de TI e Estratégia de Negócios nos Operadores Logísticos. In: XXXI Encontro da ANPAD, 2001, Rio de Janeiro, RJ. Anais... Rio de Janeiro: EnANPAD, 2007. 1 CD-ROM.

CARVAlHO, R. B. Tecnologia da informação aplicada à gestão do conhecimento. Belo Horizonte: Editora Arte, 2003.

CASTRO, S. A. de; GONÇALVES, P. R.; CAZARINI, E. W. O uso do OLAP na estratégia de vendas em uma indústria de calçados alavancando a gestão de cadeia de suprimentos. Encontro Nacional de Engenharia de Produção, XXIV ENEGEP, Florianópolis, SC, 2004. 1 CD-ROM.

CODD, E. F.; CODD, S. B.; SALLEY, C.T. Providing OLAP to user-analysts: an IT mandate. 24 p. Disponível em: $<\mathrm{http}$ ://dev.hyperion.com/resource_library/white_papers/ providing_olap_to_ user_analysts.pdf $>$. Acesso em 28 de nov. 2008.

DECKER, K.; FOCARDI; S. Technology Overview: A Report on Data Mining. Technical report, Swiss Center for Scientific Computing, fev. de 1995. Disponível em: <http://www.cscs.ch >. Acesso em: março de 2008.

FAYYAD, U.; PIATETSKY-SHAPIRO, G.; SMYTH, P. Knowledge discovery and data mining: Towards a unifying framework. Proceedings...In: Proceedings of the Second International Conference on Data Mining and Knowldege Discovery, pp. 82-88. AAAI Press, Menlo Park, US., 1996.

GIMENEZ, F. A. P. O estrategista na pequena empresa. Maringá: Universidade Estadual de Maringá, 2000.176 p.

HAYES, R. H.; WHEELWRIGHT, S. C. Restoring our competitive edge: competing through manufacturing. New York: John Wiley \& Sons, 1984. 427 p.

HORST, P. S.; MONARD, M. C. Um sistema computacional para avaliação de regras induzidas por algoritmos de aprendizado de máquina. Proceedings... In Proceedings of IBERAMIA-SBIA 2000 Open Discussion Track, pp. 167176. Nov. de 2000.

INFO CORPORATE. Mudanças na TI. InfoCorporate: A revista do CIO, nº 12, p. 30 - 41, set. 2004.

INMON, W. H. Como construir o Data Warehouse. Rio de Janeiro: Editora Campus, 1997.

KAPLAN, R. S.; NORTON, D. P. The Balanced Scorecard: translating strategy into action. Boston, Mass.: Harvard Business School Press, 1996. 322 p.

KIMBALL, R. Data Warehouse Toolkit. São Paulo: Makron Books, 1997.

KIMBALL, R.; ROSS, M. Data Warehouse toolkit: the complete guide to dimensional modeling. São Paulo: Makron Books, 2002. 464 p.

LAUDON, K. C.; LAUDON, J. P. Management information systems: managing the digital firm. $8^{\text {a }}$ ed. Upper Saddle River, NJ: Prentice-Hall, 2004. 534 p.

LI, B. Data Mining NOW: a survey and thesis proposal. Technical report, New York University. Jan, 1996.

MINTZBERG, H. Five Ps for strategy. In: MINTZBERG, H.; QUINN, J. B. The strategy process, concepts, contexts, cases. 2. ed. Upper Saddle River, NJ: Prentice-Hall, 1991. p.12. 
MINTZBERG, H.; QUINN, J. B. O processo da estratégia. 3ª ed. Porto Alegre: Bookman, 2001. 404 p.

NOGUEIRA, A. R. R.; MOREIRA, P. A. C. Alinhamento estratégico e construção do futuro: um estudo exploratório. In: XXI Encontro da ANPAD, 1997, Rio das Pedras, RJ. Anais... Rio das Pedras: EnANPAD, 1997. 1 CD-ROM.

O'BRIEN, J. A. Sistemas de informação e as decisões gerenciais na era da Internet. 2a ed. São Paulo: Saraiva, 2004. $431 \mathrm{p}$.

OLIVEIRA, R. M.; MAÇADA, C. G. Ligando estratégia e investimentos em infra-estrutura de TI: uma abordagem de máximas em um terminal de containers. RAUSP. v. 38, n. 4, out./ nov./ dez. 2003.

PARK, C-S.; KIM, M. H.; LEE, Y-J. Finding an efficient rewrinting of OLAP queries using materialized views in data warehouses. Decision Suppot Systems. n. 32, pp.379-399, 2002.

PIRES, N. C. M.; KATO, H. T. A Influência da Estratégia na Informatização e no Desempenho das Concessionárias de Automóveis Brasileiras. In: XXXI Encontro da ANPAD, 2001, Rio de Janeiro, RJ. Anais... Rio de Janeiro: EnANPAD, 2007. 1 CD-ROM.

PIRES, S. Gestão estratégica da produção. Piracicaba: UNIMEP, 1995. 270 p.

POE, V., KLAUBER, P.; BROBST, S. Building a Data Warehouse for Decision Support. 2 ed. New Jersey: Prentice-Hall, 1998. 285 p.

PORTER, M. E. Da vantagem competitiva à estratégia corporativa. In: MONTGOMERY, C. A.; PORTER M. E. Estratégia: a busca da vantagem competitiva. Rio de Janeiro: Campus, 1998. Parte IV, Cap. 1, p. 237-269.

REZENDE, D. A.; GUAGLIARDI, J. A. Alinhamento, contribuições e relações da tecnologia da informação com planos e planejamentos municipais: survey em prefeituras brasileiras. RAUSP. v. 42, n. 4, out./ nov./ dez. 2007.

RICHTER, W. Virtual Communities und Customer Relationship Management. 2001. Tese - Institut für Informationsverarbeitung und Computergestützte neue Medien (IICM), Technische Universität Graz, A-8010 Graz. Disponível em: <http://www.iicm.edu/wrichter/thesis-final/thesis-final.html>. Acesso em: 27 de nov. 2008.

RODRIGUES, J. dos R. G.; NUNES, P. M. O uso do Balanced Scorecard como núcleo de Business Intelligence: um poderoso habilitador da excelência das decisões sobre temas qualitativos e estratégicos da organização moderna. In: XXV Encontro da ANPAD, 2001, Campinas, SP. Anais... Campinas: EnANPAD, 2001. 1 CD-ROM.

SACCOL, A. Z.; MACADAR, M. A.; PEDRON, C. D.; LIBERALI NETO, G.; CAZELLA, S. C. Algum tempo depois... como grandes empresas brasileiras avaliam o impacto dos sistemas ERP sobre suas variáveis estratégicas. In: XXVI Encontro da ANPAD, 2002, Salvador, BA. Anais... Salvador: EnANPAD, 2002. 1 CD-ROM.

SHIM, J.P; WARKENTIN, M., COURTNEY, J. F.; POWER, D. J.; SHARDA, R.; CARLSSON, C. Past, present, and future of decision support technology. Decision Support System, v. 33, p. 111-126. 2002.

cross ${ }^{\text {ref }}$

SIMON, H. A. The new science of management decisions. Upper Saddle River, NJ: Prentice Hall, 1977.175 p.

SISNEMA INFORMÁTICA. Evolução do OLAP. Disponível em: <http://sisnema.com.br/Materias/idmat014848. htm>. Acesso em: 10 de jan. 2009.

SLACK, N.; CHAMBERS, S.; HARLAND, C.; HARRISON, A.; JOHNSTON, R. Administração da Produção. São Paulo: Atlas, 2002. 726 p.

SORDI, J. O.; CONTADOR, J. C. Integração dos sistemas de informação à estratégia da organização por meio do modelo de campos e armas da competição. RAUSP. v. 40, n. 2, abr./ mai./ jun. 2005.

THOMSEN, E. OLAP: construindo sistemas de informações multidimensionais. Rio de Janeiro: Campus, 2002. 708p.

TURBAN, E.; ARONSON, J. E. Decision support systems and intelligent systems. $6^{\mathrm{a}}$ ed. Upper Saddle River, NJ: Prentice-Hall, 2001. 867 p.

TURBAN, E.; RAINER JR, R. K.; POTTER, R. E. Administração de tecnologia da informação: teoria e prática. $3^{\mathrm{a}}$ ed. Rio de Janeiro: Elsevier, 2005. 618 p. 
YIN, R.K. Case study research: design and methods. Newbury Park, California: Sage Publications, 1994. 166p.

\section{Dados dos autores:}

Nome completo: Stella Jacyszyn Bachega

Filiação institucional: Universidade Federal de Goiás / Universidade Federal de São Carlos

Departamento: Engenharia de Produção

Função ou cargo ocupado: Professora Assistente / Doutoranda

Endereço para correspondência: Av. Dr. Lamartine Pinto de Avelar, 1120, Setor Universitário,

Catalão, Goiás, Brasil, CEP: 75.704-020

Telefones para contato: (64) 3441-1510

e-mail:stella@dep.ufscar.br

Nome completo: Néocles Alves Pereira

Filiação institucional: Universidade Federal de São Carlos

Departamento: Engenharia de Produção

Função ou cargo ocupado: Professor Associado

Endereço completo: Rodovia Washington Luís, Km 235, São Carlos, São Paulo, Brasil, CEP: $13.565-905$

Telefones: (16) 3351-9509

e-mail:dnap@power.ufscar.br

\section{Nome completo: Paulo Rogério Politano}

Filiação institucional: Universidade Federal de São Carlos

Departamento: Computação

Função ou cargo ocupado: Professor Associado

Endereço completo: Rodovia Washington Luís, Km 235, São Carlos, São Paulo, Brasil, CEP: 13.565-905; Telefones: (16) 3351-8232; e-mail: paulo@dc.ufscar.br 